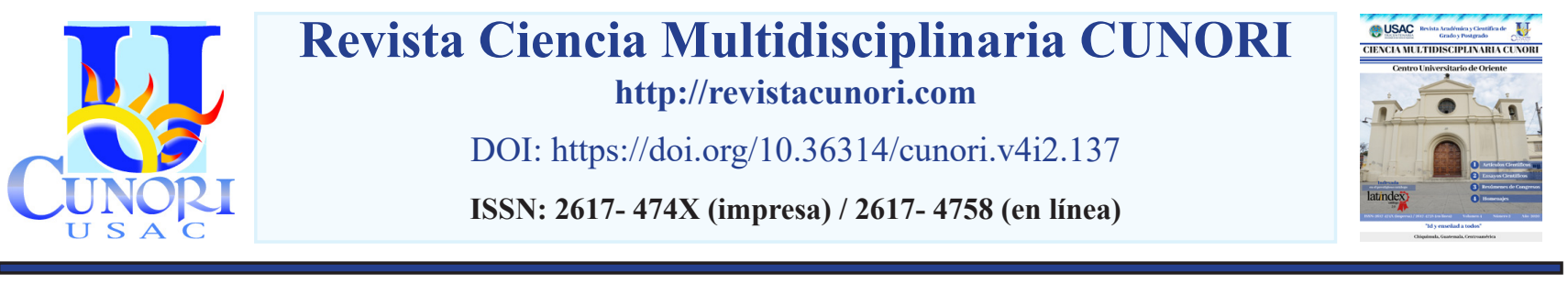

Referencia del artículo

Valdés Avila, I. M. (2020). Incertidumbre con el COVID-19 y los campos morfogenéticos. Revista Ciencia Multidisciplinaria Cunori, 4(2), 133-140. https://doi.org/10.36314/cunori.v4i2.137

\title{
Incertidumbre con el COVID-19 y los campos morfogenéticos
}

\section{Uncertainty with COVID-19 and morphogenetic fields}

\author{
Indira Marizela Valdés Avila \\ Doctorado en Investigación en Educación \\ Centro Universitario de Oriente, Universidad de San Carlos de Guatemala \\ https://orcid.org/0000-0001-7895-9631 \\ Recibido: 15 de mayo de 2020 / Revisado: 17 de mayo de 2020 / Aceptado: 05 de junio de 2020
}

Disponible en internet el 30 de octubre de 2020

*Autor para correspondencia.

Correo electrónico: indira.valdes@cunori.edu.gt

Resumen

Gl mundo está experimentando la mayor incertidumbre ante un fenómeno inesperado, un virus que ha traspasado fronteras, Emientras el ser humano lucha por sobrevivir, los datos demuestran el comportamiento exponencial de un virus categorizado como pandemia Covid-19. Esta pandemia afecta a los diferentes grupos sociales en una perspectiva económica, de salud, de educación, política, psicosomática, entre otros. La ciencia tras años ha creado teorías para explicar la evolución, ante la crisis causada por Covid-19, al ser humano se le presentan nuevos escenarios en los que debe crear sus planes de sobrevivencia, los campos morfogenéticos se relaciona con la física moderna, el almacenamiento de información, registros de datos que se encuentran en la memoria por medio de la resonancia mórfica, esos sucesos registrados en el pasado de nuestros ancestros, pueden aparecer inconscientemente en la actualidad y tener una reacción en las creación de nuevos seres.

Palabras clave: covid-19, salud, transdisiciplinariedad, sociedad, campos morfogenéticos

\begin{abstract}
$\mathrm{T}$ he world is experiencing the greatest uncertainty in the face of an unexpected phenomenon, a virus that has crossed borders, while the human being struggles to survive, the data demonstrates the exponential behavior of a virus categorized as a Covid-19 pandemic. This pandemic affects different social groups from an economic, health, educational, political, psychosomatic perspective, among others. Science after years has created theories to explain evolution, before the crisis caused by Covid-19 the human being is presented with new scenarios in which he must create his survival plans, the Morphogenetic fields are related to modern physics, storage of information, data records found in memory through morphic resonance, those events recorded in the past of our ancestors, may appear unconsciously today and have a reaction in the creation of new beings.
\end{abstract}

Keywords: covid-19, health, transdisciplinarity, society, morphogenetic fields 


\section{Introducción}

La aparición de un virus que ha traspasado fronteras, aislando a la humanidad, países compitiendo por ser el primero en crear la cura, una vacuna que puede representar un poder que traspase fronteras. El mundo está experimentando la mayor incertidumbre ante un fenómeno inesperado, para algunas personas representa miedo, para otras personas es una mentira, una guerra biológica, muchas opiniones existen acerca de la nueva rama del coronavirus, lo que si es cierto es que el ser humano lucha por sobrevivir, ante un mundo desconocido no solo para la mente sino que de igual forma para el sistema inmunológico del ser humano, donde la formación de los genes es un elemento importante para ser analizado, aparte surgen cambios en diferentes áreas de la vida cotidiana.

\section{Materiales y métodos}

Se estableció un dialogo con los autores de la ciencias de la complejidad como Cajal, Hubbard, Maldonado, McClean y Sheldrake.

\section{Resultados}

Para iniciar debemos conocer que es el coronavirus o COVID19, según la OMS los coronavirus son una extensa familia de virus que pueden causar enfermedades tanto en animales como en humanos. En los humanos, se sabe que varios coronavirus causan infecciones respiratorias que pueden ir desde el resfriado común hasta enfermedades más graves como el síndrome respiratorio de Oriente Medio (MERS) y el síndrome respiratorio agudo severo (SRAS). El coronavirus que se ha descubierto más recientemente causa la enfermedad por coronavirus COVID-19 (Organización Mundial de la Salud [OMS], 2020)

El aislamiento es una necesidad que surge para evitar que el virus se propague, debido a que a través de las gotículas procedentes de la nariz o la boca de una persona infectada se contagie a otras personas, una de las recomendaciones que ha establecido la OMS es mantenerse a más de 1 metro ( 3 pies) de distancia de una persona que se encuentre enferma.

En una noticia publicada por CNN en Español, da a conocer donde se iniciaron los primeros casos del COVID-19 siendo durando un tiempo un suspenso hasta que decidieron dar información al mundo de lo que estaba ocurriendo: "Los primeros casos de neumonía detectados en Wuhan son reportados a la OMS. Durante este periodo, el virus es aún desconocido. Los casos ocurren entre el 12 y el 29 de diciembre, según las autoridades de salud de Wuhan”. (CNN Español, 2020).

La conducta de las personas está íntimamente relacionado con el ambiente que los rodea, la reacción ante la incertidumbre nos presenta el escenario de un sistema complejo que exige a una sociedad su evolución, ¿Cómo sobrevivir?, y no es solamente al coronavirus sino al nuevo estilo de vida adquirido por el riesgo de contraerlo, el miedo que ha impuesto a las personas en todo el mundo, tanto países desarrollados como en países en vías de desarrollo, puesto que cada sector demanda nuevos modelos 
de sistemas para realizar determinadas actividades, por ejemplo el sector salud demanda equipamiento como respiradores y protección para sus empleados, la educación para cumplir con su objetivo vuelve casi obligatorio el uso del internet, la comunicación entre amigos, familiares es por medio de herramientas que se encuentran en la web y Apps como WhatsApp, la intercomunicación a través de la red más grande nos une por medio de datos de información pero separa a las personas físicamente.

Es necesario analizar la situación del escenario que actualmente están viviendo las personas ante el cambio de la forma en que se relacionan comúnmente las personas, tradicional versus lo que demanda la sociedad actualmente; el no salir de casa, la no convivencia física con otras personas, interacción con compañeros de trabajo, de estudio, no poder caminar libremente en el parque de la ciudad, entre otras actividades cotidianas de una persona ordinaria, el privar a las personas de lo que es natural en su medio ambiente genera estrés, consecuentemente hasta violencia intrafamiliar. Como lo demuestra la prensa en la edición del 21 de abril de 2020 en Guatemala "las denuncias por violencia psicológica sobresalen en las estadísticas, le siguen las denuncias por violencia física y sexual; lamentamos que este tipo de violencia esté en las primeras posiciones en el ámbito nivel nacional, a pesar de la emergencia por el coronavirus, la violencia contra la mujer no se detiene”, señaló el Fiscal Distrital. (Cordero, 2020).

El miedo inunda a las personas, problemas de la situación actual se manifiestan en enfermedades psicológicas, físicas, donde el poder de la mente ante factores negativos puede perjudicar la parte física del cuerpo humano. El estrés que genera el miedo por preocupación, temor a enfermarse, el sentir vivir en un encierro como una privacidad a la locomoción, debilita el sistema inmunológica bajando sus defensas, el sistema humano no sabe cómo enfrentar la crisis que ahora forma parte del entorno como cargas de energías que lo rodean, recordemos que el cerebro de una persona funciona a través de las neuronas que envían señales eléctricas para ejecutar el movimiento de alguna extremidad, o el funcionamiento de los órganos de sistema humano.

\section{La evolución}

Darwin creo la teoría evolucionista, muy famosa en su época pero caracterizada por no saber cómo sucedía esa evolución: "La variación es una característica de las poblaciones naturales y cada población produce más progenie de la que su medio ambiente puede manejar. Las consecuencias de esta sobreproducción son que aquellos individuos con la mejor aptitud genética para el medio ambiente producirán descendencia que puede competir con más éxito en ese ambiente". la generación posterior tendrá una mayor representación de estos descendientes y la población habrá evolucionado " (McClean, 1997). El incorporar en su teoría que el hombre desciende del mono, creó algunas dudas en científicos que luego crearían la teoría de los genes como fue el caso de Mendel aportando las piezas que faltaban a la estructura erigida por Darwin: En 1856, Mendel inició una serie de experimentos extraordinarios en el jardín del monasterio agustino de St. Thomas de Brünn, actualmen ᄀte en Brno, República Checa. A lo largo de los siete años siguientes fue capaz de crear más de 29.000 especies de guisantes, lo que haría que llegara a ser conocido como el fundador de la genética moderna (Mark, 2010). 
Los científicos a través de los siglos han buscado la verdad absoluta, creando dogmas que vuelven una proposición una verdad absoluta, generando que en cada época tenga su dogma, pero actualmente los científicos presentan un más allá; donde las teorías son relativas y no absolutas. Los paradigmas que por años han limitado la mente del ser humano avanzan en el tiempo, como un progreso, lo que hace que la mente humana cambie su forma de pensar. El temor al cambio es muy común en el ser humano, el no querer romper las barreras que permiten que su mente vea más allá de los obstáculos tradicionales que la bloquean, pero es un bloqueo que hay que derribar. El fin del materialismo, se ha llegado por medio de investigaciones científicas que demuestran que el materialismo llega a su fin.

La nueva percepción del mundo se puede alterar, como está sucediendo actualmente en el presente año 2020, con un virus que el sistema inmunológico del ser humano debe combatir y crear las defensas que no tiene para sobrevivir, por otra parte en el entorno social, las personas deben transformar en su sentido común la forma de interactuar con las personas, una nueva sociedad.

\section{Campos morfogenéticos y la biología del desarrollo}

El cuerpo del ser humano tiene un campo corporal conocido como campo morfogenético, es una concepción holística o integradora de la organización viviente. Los campos del cuerpo son holísticos, si un sistema de un campo es dividido se crea un nuevo campo, completo con todas las características al cual pertenecía antes de ser un campo independiente. Por ejemplo en la Biología del desarrollo, se pueden analizar los campos magnéticos si dividimos un imán en partes, cada parte vuelve a ser un imán y funciona como un imán, una persona al perder una extremidad como un brazo aunque el brazo ya no exista físicamente, la persona tiene la sensación de la presencia de ese brazo, es el campo mórfico que existe, aunque no pueda volver a crecer ese brazo como en otras especies, lo que sí podría llegar a permitir la tecnología es un sistema electromecánico que permita controlar un brazo robótico a través de señales emitidas por el cerebro humano.

El biólogo Rupert Sheldrake, comparte en su sitio oficial la siguiente definición: "Los campos morfogenéticos no son estáticos, sino que evolucionan. Por ejemplo: los campos de los perros y caniches afganos se han vuelto diferentes de los de sus ancestros comunes, los lobos. ¿Cómo se heredan estos campos? se transmitan de miembros pasados de la especie a través de una especie de resonancia no local, llamada resonancia mórfica." (Sheldrake, 2020). Los seres humanos desde la concepción es el inicio a una nueva vida, una única célula que crece y se divide, las células saben cómo es el proceso, se dividen, por ejemplo para crear cada organismo del ser humano, las células se dividen, empiezan a dar forma al organismo y saben cómo hacerlo. El Campo mórfico es el encargado de conectar con el ADN y la información genética del cuerpo, la idea holística es que el campo corporal decide sincronizar todos los elementos para que desempeñen su papel como debe de ser en la creación y desarrollo del ser humano, los campos morfogenéticos son sistemas de información, porque a través de la evolución del ser humano almacena la información para utilizarla de mejor manera en función del desarrollo del organismo, ayuda a los cuerpos a recuperarse de enfermedades o lesiones, el cuerpo humano contiene información estructurada que se identifica como un campo de energía, que ejerce un control sobre el sistema humano. 
Existe el campo corporal, es el encargado de decidir qué información se extrae del ADN, para desarrollar un nuevo ser viviente. Los campos mórficos poseen una memoria sobre información almacenada del sistema humano y juega un papel importante como memoria probabilística que permiten la evolución a través de la Resonancia Mórfica.

\section{Resonancia mórfica}

Un ser vivo posee una forma, si analizamos un individuo de una especie, observaremos que su forma es similar a otros individuos de la misma especie, la resonancia mórfica es la influencia de lo similar sobre otros similares en el tiempo y el espacio, es por medio de la memoria que los campos mórficos crean la forma de un individuo basándose en la información de lo que ya ocurrió en esa especie anteriormente. La resonancia mórfica es el conector donde está la información de los patrones que forman a los seres vivos entre ellos el ser humano, estos patrones cambiarán al ser humano como un desplazamiento a través de la transferencia de información según el patrón del ser humano en el pasado, esto explica el por qué las similitudes entre las familias y a la vez la evolución de las especies a nivel general. La influencia mórfica de un pasado no está limitada, pero si restringidas por probabilidades de que ocurra una cosa y no otra en le formación de una estructura de un organismo vivo, según: "El promediado automático de las formas anteriores provoca una distribución de probabilidad espacial del campo morfogenético o, dicho en otras palabras, una “estructura de probabilidad”. Es la estructura de probabilidad de un campo morfogenético la que determina el posible estado de un sistema que se halle bajo su influencia con arreglo a los estados reales de todos los sistemas pasados similares. En este sentido, la forma más probable que asuma el sistema será la que más frecuente se haya presentado" (Sheldrake, 2011).

\section{Información desde afuera y una nueva civilización}

En el siglo XVII Rene Descartes explicaba la teoría de la vida como una máquina, en la actualidad este concepto ha dejado de ser válido, porque se representaba como el interior del organismo, la física moderna válida que la información existe fuera del organismo por medio de conexiones y la memoria de hace siglos atrás sobre el ser humano, hacen que se refleje en la actualidad con cambios en los patrones a través de la evolución y esto es resultado de los campos mórficos, abriendo camino a una nueva civilización, Carlos Maldonado explica cómo se puede hacer posible esa nueva civilización, a partir de que el ser humano se presente ante una emergencia. "En cualquier caso, una mayor sensibilidad y una reflexión serena y cuidadosa permiten observar, con interés, que nos encontramos en el proceso de pensar y hacer posible otra civilización. No ya, simplemente, otra sociedad, otras formas de organización u otra cultura. Más radicalmente, asistimos a la emergencia, ciertamente aún incipiente pero ya morfológicamente gestada y en desarrollo, de una nueva civilización. En verdad, se trata de un acontecimiento singular en la historia de una familia como la humana; o de un planeta habitado, como la Tierra, que no se presenta en muchos cientos y varios miles de años. Una oportunidad singular" (Maldonado, 2016).

\section{Inconsciente colectivo}

El almacenamiento de información son registros de datos que se encuentran en la memoria por medio de la resonancia magnética, esos sucesos registrados en el pasado de nuestros ancestros, pueden aparecer inconscientemente en la actualidad o en el futuro, esto es conocido como el Inconsciente colectivo. 
"La intuición nos ayuda a comprender qué se debe hacer y que no se debe hacer. En resumen, la intuición nos ayuda a arriesgar lo menos posible entre situaciones inciertas. Cuanto mayor es nuestra experiencia más funcional la intuición. La intuición no es extrasensorial porque no introduce conocimiento desconocido y externo en nuestro conocimiento. Este sentido reelabora la información que ya tenemos. Por lo tanto, el sexto sentido opera racionalmente en datos conocidos. Por el contrario, el séptimo sentido elabora de manera completamente irracional e impredecible datos e información que a menudo nunca han tocado nuestra conciencia y nuestro conocimiento. Es decir, el séptimo sentido nos introduce a realidades ajenas a nuestra vida diaria y a nuestra experiencia. El término séptimo sentido puede definir bien algunas propiedades conocidas más científicamente como percepciones extrasensoriales, o ESP (abreviaturas Percepción sensorial extra)” (Cajal, 2019).

El inconsciente colectivo modula la forma en que los seres humanos piensan, sienten y actúan, las personas heredaran las estructuras psicológicas que se han construido a través de los nuevos estilos de relaciones sociales que se están dando en el mundo actual un sistema complejo ante la pandemia del COVID-19. Existen un conjunto de imágenes ancestrales que forman una base de información que es común en la humanidad, al igual que en el pasado sucederá con la creación de esas imágenes como patrones de lo que vive el mundo actualmente, pasando de civilización en civilización, el ser humano no se desarrolla de forma aislada, sino que influye su entorno social, heredando patrones emocionales y de conducta, lo cual producirá nuevas estructuras de formas en la evolución del ser humano con la capacidad de un sistema del cuerpo humano capaz de poder vivir en un mundo con coronavirus, con un sistema inmunológico adecuado para ese entorno.

\section{Evolución cósmica}

La transferencia de información que sucede de un patrón para la creación de un nuevo patrón, en una versión evolucionada, con información actualizada, es lo que se llama memoria madura "la mente analítica consiste en el "yo" (el centro de conciencia), toda la capacidad computacional del individuo y los bancos estándar de memoria, que están llenos con todas las percepciones pasadas del individuo, despierto o dormido con normalidad. No falta ningún dato en estos bancos estándar, todos están allí, a no ser que haya defectos físicos orgánicos con todo su movimiento, color, sonido, tacto, olfato y todos los demás sentidos" (Hubbard, 2007).

\section{Discusión}

La formación de las nuevas estructuras que forman los campos morfogenéticos para la creación de los seres humanos, son capaces de evolucionar; ante las situaciones complejas que se presentan en un momento en la vida, espacio y tiempo, interactuando en el ahora: los campos mórficos, especialmente los campos morfogenéticos, la biología, la resonancia mórfica, el inconsciente colectivo, esto forma parte de la evolución humana con información más reciente para la memoria madura, que hace capaz que la información externa de los campos mórficos creen la nuevas formas de estructuras internas de los organismos del ser humano, esto creará en la memoria madura nuevos patrones para una nueva civilización del ser humano evolucionado dejando atrás lo que un día representó el riesgo de supervivencia ante el COVID-19. 


\section{Referencias}

Cajal, V. (2019). Enredo cuántico e inconsciente colectivo. Física y metafísica del universo. p.57, 58. Editorial Bruno del médico. Sabaudia, Italia.

CNN Español (2020). Cronología del conoravirus así comenzó y se extendió. https://cnnespanol.cnn. com/2020/02/20/cronologia-del-coronavirus-asi-comenzo-y-se-extendio-el-virus-que-pone-enalerta-al-mundo/

Holograma (2020). Rupert Sheldrake es entrevistado por Marisa Escasany en Holograma. https://www. youtube.com/watch? $\mathrm{v}=\mathrm{oUWyAbRgRCM}$.

Hubbard, L. R. (2007). Dianética La ciencia moderna de la salud mental. p.vii. Editorial Bridge Publications, Inc. California, Estados Unidos.

Maldonado, C. E. (2016). Complejidad de las ciencias sociales y de las otras ciencias y disciplinas. p.280. Editorial Desde Abajo, Bogotá, Colombia.

McClean, P. (1997). Darwin's theory of evolution by natural selection (La teoría de Darwin sobre la evolución mediante selección natural). En Population and evolutionary genetics. en https://www.ndsu. edu/pubweb/ mcclean/plsc431/popgen/popgen5.htm

OMS. (2020). Preguntas y respuestas sobre la enfermedad por coronavirus (COVID-19). Organización Mundial de la Salud en https://www.who.int/es/emergencies/diseases/novel-coronavirus-2019/ advice-for-public/q-a-coronaviruses

Sheldrake, R. (2011). Una nueva ciencia de la vida. Editorial Kairós. p.158. España.

Sheldrake, R. (2020). Resonancia Mórfica y Campos Mórficos - Una Introducción. https://www.sheldrake. org/espanol/resonancia-morfica-y-campos-morficos-una-introduccion

\section{Sobre la autora}

\section{Indira Marizela Valdés Avila}

Ingeniera en Sistemas de Información y Ciencias de la Computación, egresada de la Universidad Mariano Gálvez de Guatemala, con Maestría en Administración de Recursos Humanos del Centro Universitario de Oriente, actualmente estudia el Doctorado en investigación en Educación de la Universidad de San Carlos de Guatemala, ha realizado investigaciones en el campo de ciencias exactas y empresariales como las que se mencionan: Árboles de Decisiones y los Sistemas de Información, Herramientas de apoyo para las Organizaciones, El Papel de la Mujer en el ámbito del Liderazgo, El Servicio al Cliente para alcanzar la Calidad Total, El Desarrollo como motivador del Recurso Humano, La Provisión de Recurso Humano y Las Tics, Las Empresas Familiares y la Globalización. 
Copyright (c) Indira Marizela Valdéz Avila

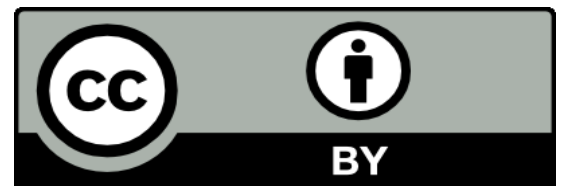

Este texto está protegido por una licencia CreativeCommons 4.0.

Usted es libre para compartir, copiar y redistribuir el material en cualquier medio o formato y adaptar el documento, remezclar, transformar y crear a partir del material para cualquier propósito, incluso comercialmente, siempre que cumpla la condición de atribución: usted debe reconocer el crédito de una obra de manera adecuada, proporcionar un enlace a la licencia, e indicar si se han realizado cambios. Puede hacerlo en cualquier forma razonable, pero no de forma tal que sugiera que tiene el apoyo del licenciante o lo recibe por el uso que hace. 